Accepted manuscript to Combustion and Flame

\title{
Dynamic responses of counterflow nonpremixed flames to AC electric
}

\section{field}

\author{
Dae Geun Park ${ }^{1,2 *}$, Suk Ho Chung ${ }^{1}$, Min Suk Cha ${ }^{1 \dagger}$ \\ ${ }^{1}$ King Abdullah University of Science and Technology (KAUST) \\ Clean Combustion Research Center (CCRC) and Physical Science and Engineering \\ Division (PSE) \\ Thuwal 23955-6900, Saudi Arabia \\ ${ }^{2}$ Korea Institute of Industrial Technology (KITECH) \\ Thermochemical Energy System R\&D Group \\ Cheonan 31056, Republic of Korea
}

\begin{abstract}
Although ionic wind has been observed to play important roles in the effects of electric fields on flames, there is a lack of systematic quantification of ionic wind that allows interpretation of a flame's responses to electric fields. Here, we report on various responses of nonpremixed flames, such as the flame's dynamic responses and the generation of bidirectional ionic wind, in relation to the applied voltage and frequency of an alternating current (AC) in a counterflow burner. We find that although the Lorentz force acting on charged molecules initiates related effects, each effect is both complex and different. When the applied voltage is in the sub-saturated regime (small) as determined by the voltage-current behavior, flame movements and flow motion are minimally affected. However, when the applied voltage is in the saturated regime (large), flame oscillation occurs and a bidirectional ionic wind is generated that creates double-stagnation planes. The flame's oscillatory motion could be categorized in the transport-limited regime and in the oscillatory decaying regime, suggesting a strong dependence of the motion on the configuration of the burner. We also observed bidirectional ionic wind in visibly stable flames at higher $\mathrm{AC}$ frequencies. We present detailed explanations for flame behaviors, electric currents, and flow characteristics under various experimental conditions.
\end{abstract}

Keywords: counterflow, nonpremixed flame, ionic wind, alternating current

\footnotetext{
${ }^{*}$ Current address: dgpark@kitech.re.kr, Korea Institute of Industrial Technology (KITECH)

${ }^{\dagger}$ Corresponding author: min.cha@kaust.edu.sa
} 


\section{Introduction}

The effects of electric fields on flames have been extensively studied, highlighting various phenomena, including reduced soot emission [1]-[5], enhanced flame propagation [6]-[10], and augmented flame stability [11]-[14]. Among various hypothetical effects of an electric field, ionic wind has attracted keen interest [15]-[17]. Most related studies have hypothesized that ionic wind leads to observed phenomenological effects. When a hydrocarbon flame is exposed to an electric field, the charged particles of positive ions, negative ions, and electrons generated via chemi-ionization [18]-[20] are affected by the Lorentz force and a directional diffusion based on mobility occurs. Then, as a consequence of an electric body force acting on a fluid volume, an ionic wind can be generated [21]-[23].

For example, ionic wind-driven flow-field modification was speculated to cause reduction in soot formation under a direct current (DC) electric field [1]; ionic wind-driven hydrodynamic instability and/or a modification of the transport property was hypothesized to lead to the faster burning character of outwardly propagating premixed flames under an alternating current (AC) electric field [6]; ionic wind improved flame stability in a numerical study of nonpremixed laminar jet flames under a DC field [11]; and, recently, bidirectional ionic wind blowing from a flame to both electrodes was observed in nonpremixed counterflow flames [16] followed by generalized visualization in premixed and nonpremixed jet flames with DC and AC fields [24], suggesting new understanding of the nature of ionic wind and its interaction with flames' structures. As a result of the insight of the bidirectional ionic wind, we proved that a propagation speed of a nonpremixed edge flame could be augmented [25], [26] or retarded [27] depending on a relative direction of electric field with 
respect to that of flame propagation. This implies that we should be able to actively control a propagating character of a flame using electric field.

When AC electric fields were applied to a flame, steady modification of the flow field could be observed using schlieren imaging when the AC frequency was higher than $\mathrm{O}\left(10^{2}\right)$ $\mathrm{Hz}$ [15]. This is somewhat counterintuitive given experimental observations of visibly steady flames, suggesting that there should be no ionic wind with the frequencies higher than $1 \mathrm{kHz}$. In the streamline visualization of premixed and nonpremixed jet flames [24], the steady looking flames for the $\mathrm{AC}$ frequency at $1 \mathrm{kHz}$ also underwent the bidirectional ionic wind. A recent velocity measurement with nonpremixed edge flames in a counterflow, annular slot burner indicated that there was a significantly affected unburned flow field at $1 \mathrm{kHz} \mathrm{AC}$ electric field, even though no discernable changes in the visible shape of the flame were observed [26]. Indeed, the stabilized location and structure of a nonpremixed flame are influenced by transport phenomena, which can be affected by a redistribution process due to ionic wind. Ruling out the effect of the ionic wind on the detailed characteristics of a flame, even when the flame is visibly steady, does therefore make no sense.

As an extended study of previously investigated effects of DC electric fields on nonpremixed flames in an axisymmetric counterflow system [16], here we experimentally investigate the effect of applied AC electric fields on counterflow, nonpremixed flames. This will finally fill the gap to completely understand the effect of electric field on nonpremixed flames in two fundamental burners (AC and DC in an axisymmetric jet [24] and DC in a counterflow [16]). In particular, we analyze the flow field, the voltage-current (V-I) behavior, and the stabilized flame position in terms of applied voltage and frequency. Detailed 
characterizations of ionic wind and the dynamic responses of flames to ionic wind are also presented.

\section{Experiment}

The experimental setup consisted of a counterflow burner, a power supply, and laser visualization systems to capture the movement of flow and the distribution of $\mathrm{OH}$ radicals (Fig. 1). Nitrogen-diluted propane and oxygen were used as the fuel and the oxidizer streams, respectively. All mean jet velocities $\left(U_{\text {jet }}\right)$ for the fuel, oxidizer, and nitrogen sheath were controlled to be the same. Two global strain rates $\left(\sigma=2 U_{\text {jet }} / L=40\right.$ and $\left.80 \mathrm{~s}^{-1}\right)$ of the cold streams were tested at separation distances $(L)$ of 1 and $2 \mathrm{~cm}$, respectively. Detailed experimental conditions are listed in Table 1.

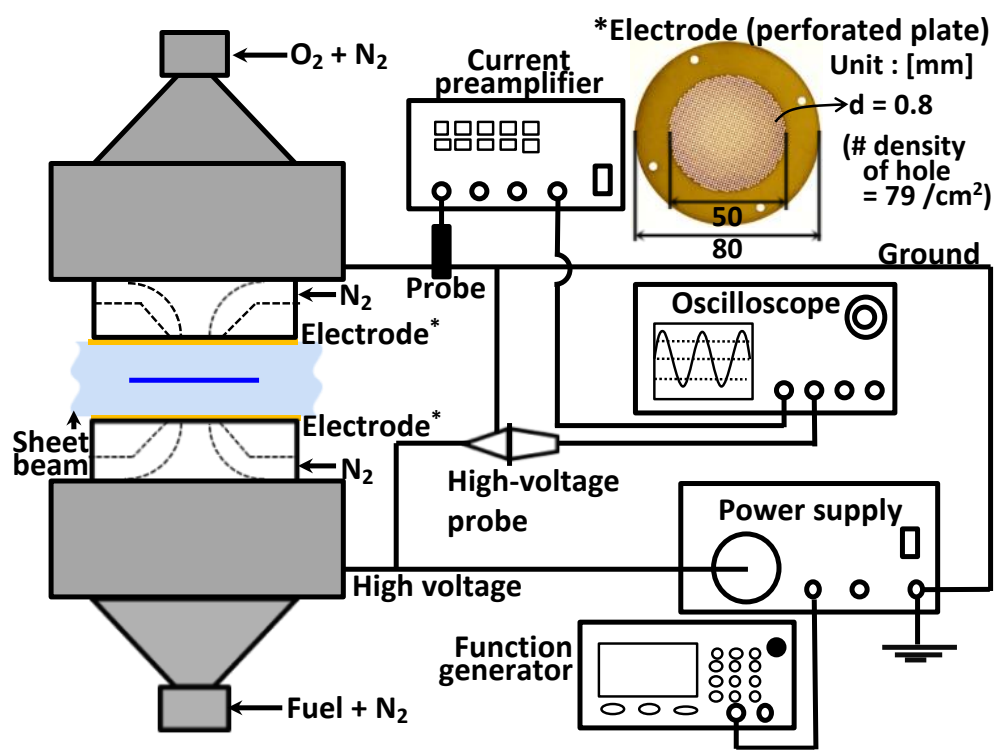

Fig. 1. Schematic of the experimental setup. 
Table 1. Experimental conditions.

\begin{tabular}{|c|c|c|c|c|c|}
\hline \multirow{2}{*}{$\begin{array}{c}\begin{array}{c}\text { Stoichiometric } \\
\text { mixture composition }\end{array} \\
\left(\mathrm{C}_{3} \mathrm{H}_{8} / \mathrm{O}_{2} / \mathrm{N}_{2}\right)\end{array}$} & \multicolumn{2}{|c|}{$\begin{array}{l}\text { Initial } \\
\text { mole fractions }\end{array}$} & \multirow{2}{*}{$\begin{array}{c}\text { Burner } \\
\text { separation } \\
L \\
{[\mathrm{~cm}]} \\
\end{array}$} & \multirow{2}{*}{$\begin{array}{c}\text { Jet } \\
\text { velocity } \\
U_{\text {jet }} \\
{[\mathrm{cm} / \mathrm{s}]} \\
\end{array}$} & \multirow{2}{*}{$\begin{array}{c}\text { Global } \\
\text { strain rate } \\
\sigma \\
{\left[\mathrm{s}^{-1}\right]}\end{array}$} \\
\hline & $X_{\mathrm{F}}$ & $X_{\mathrm{O} 2}$ & & & \\
\hline \multirow{4}{*}{$1 / 5 / 12$} & \multirow{4}{*}{0.111} & \multirow{4}{*}{0.566} & \multirow{2}{*}{1} & 20 & $40^{*}$ \\
\hline & & & & 40 & 80 \\
\hline & & & \multirow{2}{*}{2} & 40 & 40 \\
\hline & & & & 80 & 80 \\
\hline $1 / 5 / 24$ & 0.066 & 0.335 & 1 & 20 & 40 \\
\hline
\end{tabular}

The stoichiometric mixture fraction, $Z_{\mathrm{st}}=1 /\left(1+v Y_{\mathrm{f}} / Y_{\mathrm{o}}\right)$, was set at 0.5 for a theoretical flame position to be located at the stagnation plane of the counterflow, where $v$ is the stoichiometric mass ratio of oxygen to the fuel and $Y_{\mathrm{f}}$ and $Y_{\mathrm{o}}$ represent the mass fractions of fuel and oxygen at the supplied jets, respectively [28]. The reason for the selected flame location is to facilitate observation of the impact of ionic wind by virtue of a very small unburned axial velocity at the stagnation plane as demonstrated in a previous study using DC [16]. Also, negligible polarity effects on the electric current responses can be guaranteed when a flame is stabilized at the center of the inter-electrode gap, as demonstrated in a previous study reporting a polarity effect on the electric current with off-centered flame locations [29]. We chose a condition with an initial fuel mole fraction of $X_{\mathrm{F}}=0.111$ and an initial oxygen mole fraction of $X_{\mathrm{O} 2}=0.566$ injected with $U_{\text {jet }}=20 \mathrm{~cm} / \mathrm{s}$ at $L=1 \mathrm{~cm}$ as a reference case (baseline condition in Table 1).

A high voltage generator (Trek, 10/10B-HS) amplified a sinusoidal signal from a 
function generator (NF, WF1973). Its output was applied to the lower nozzle, while the upper nozzle was grounded. Metallic perforated plates (hole density $79 / \mathrm{cm}^{2}$, hole diameter $0.8 \mathrm{~mm}$ ) were placed on the exits of the nozzles. Because the diameter of the plate was $8 \mathrm{~cm}$ (much larger than the diameter of the nozzle) and because it sufficiently covered the surface of the whole flame, we could sustain uniform external electric fields in the flame zone. The tested AC applied voltage, $V_{a c}$, was up to $2.4 \mathrm{kV}$ (root mean square, rms) with various AC frequencies $\left(1 \leq f_{a c} \leq 1000 \mathrm{~Hz}\right)$. We used a current preamplifier (Stanford Research Systems, SR570) and a voltage probe (Tektronix, P6015A) to measure the electric current and the applied voltage, respectively, with an oscilloscope (Tektronix, MSO 2024).

An Ar-ion laser operated at $488 \mathrm{~nm}$ (Spectra-Physics, Stabilite 2017) illuminated the $\mathrm{TiO}_{2}$ seeding particles $(\sim 0.3 \mu \mathrm{m})$, and a high-speed camera (Photron, SA4) and a digital camera (Nikon, D700) captured the laser-scattered images to visualize flow fields. As reported in the previous study [16], the seeding particles were also affected by electric fields due to electron and ion attachment to the particles. However, as a result of careful elaboration, it was found that the motion of particles reasonably followed the imposed flow field except near the upper and lower walls, where flow inertia was very small and local electric field intensity was relatively high.

We also used the planar laser-induced fluorescence (PLIF) technique to visualize the $\mathrm{OH}$ radicals. Details of this technique can be found in [1].

\section{Results and discussion}

\subsection{Overall response of flames}


Figure 2 shows photographs ( $0.1 \mathrm{~s}$ exposure time) of typical flames at the baseline condition (a) as well as at $V_{a c}=2.0 \mathrm{kV}$ with various $\mathrm{AC}$ frequencies, $f_{a c}=10,100$, and 1000 $\mathrm{Hz}(\mathrm{b}-\mathrm{d})$. At $10 \mathrm{~Hz}$, the flame oscillated up and down according to the applied frequency. The exposure time, corresponding to one periodic motion $(0.1 \mathrm{~s})$, resulted in a blurred flame shape (Fig. 2b) with a seemingly double flame configuration. There were no significant difference in the flame appearances at 100 and $1000 \mathrm{~Hz}$ as compared with the baseline case.

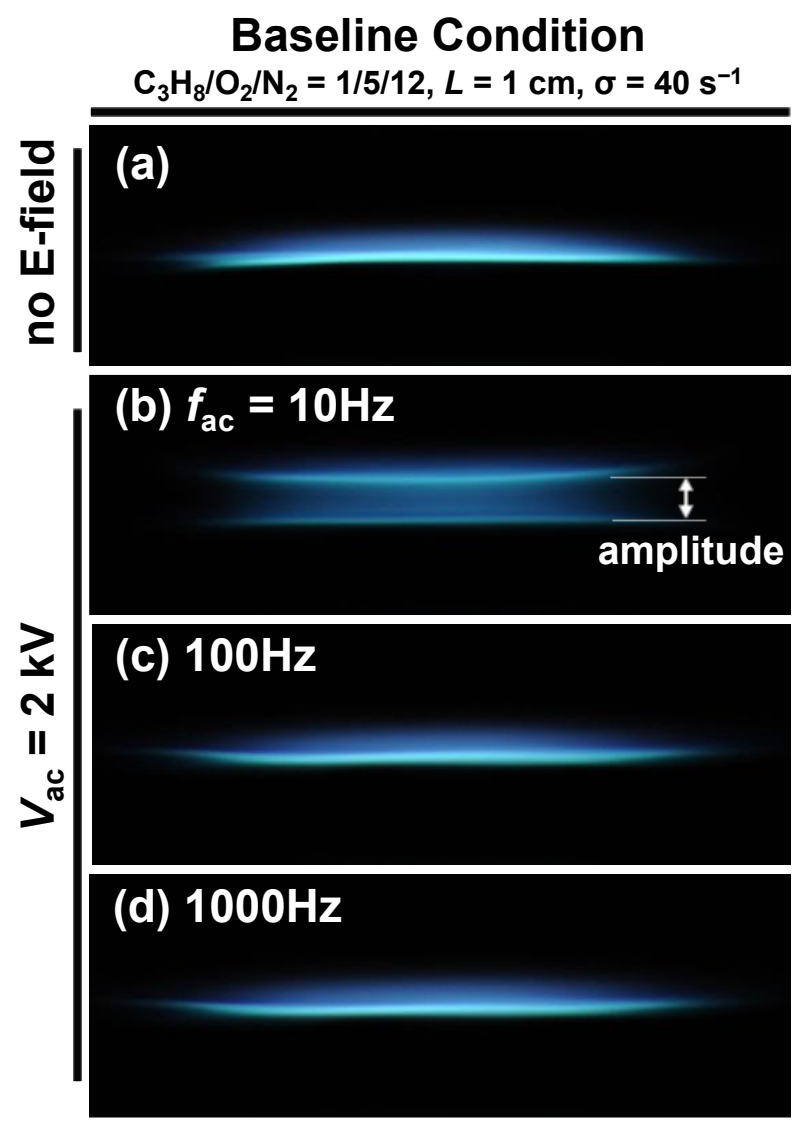

Fig. 2. Typical flames with the baseline condition: $X_{\mathrm{F}}=0.111, X_{\mathrm{O} 2}=0.566, U_{\text {jet }}=20 \mathrm{~cm} / \mathrm{s}$, and $L=1 \mathrm{~cm}\left(\mathrm{C}_{3} \mathrm{H}_{8} / \mathrm{O}_{2} / \mathrm{N}_{2}=1 / 5 / 12\right.$ and $\left.\sigma=40 \mathrm{~s}^{-1}\right)$. (a) without an applied electric field, and (b) $f_{a c}$ $=10$, (c) 100 , and (d) $1000 \mathrm{~Hz}$ at fixed $V_{a c}=2.0 \mathrm{kV}$.

As reported in previous studies [1], [3], [16], a nonpremixed flame relocates its position 
toward a cathode when a DC electric field is applied. This relocation has been attributed to the imbalance of electric body forces in two distinctive regions: one region between the flame and the cathode and the other region from the flame to the anode, where positive ions and negative charge carriers (electrons and negative ions) respectively exist with externally applied electric field. The chemi-ionization produces charged species from neutral molecules thus the amount of each charge is balanced with each other in the flame zone, such that $n_{+}=$ $n_{-}+n_{\mathrm{e}}$, where $n$ is the number density and the subscripts,+- , and e are positive ions, negative ions, and electrons, respectively. Because electrons have much higher (typically three orders of magnitude) mobility than ions have [29], electrons move very quickly from a flow volume when an external electric field is applied, resulting in a small electron density in the region between the flame and the anode as compared to a positive ion density between the flame and the cathode. When electrons carry all negative charges (no negative ions), the electron density in the region between the flame and the anode can be scaled to the ratio of the mobilities, as $\left.n_{\mathrm{e}}\right|_{\text {(flame-anode })}=\left(K_{+} / K_{\mathrm{e}}\right) n+\mid$ (flame-cathode), where $K$ indicates the mobility. Thus, the net electric body force acting on the region between the flame and the cathode is greater than between the flame and the anode. As a consequence, the flame is directed toward the cathode (lower potential side). When all negative charges are carried by negative ions, because $K_{+} / K_{-}$ $\approx 1$, the charge densities in both regions are reasonably equal, such that equal electric body forces pull the respective region in the opposite direction. A negligible flame movement can thus be expected.

This means that all hydrocarbon flames are deflected toward the cathode, although the degree of deflection depends on the portion of the negative ions among negatively charged 
species (i.e., the ratio between the electrons and the negative ions). The source of the negative ions is most likely electron attachment to oxygen molecules and water vapor, when the electrons migrate toward the anode due to external electric field. Because the stabilization location of a nonpremixed flame is determined by the stoichiometric mixture conditions, modified transport processes caused by ionic wind are also important factors in the new location of the flame. Nevertheless, previous observations [1], [3], [16] of DC electric fields showed that the flames relocated toward the cathode, indicating the crucial role of the electric body force on the flame's relocation.

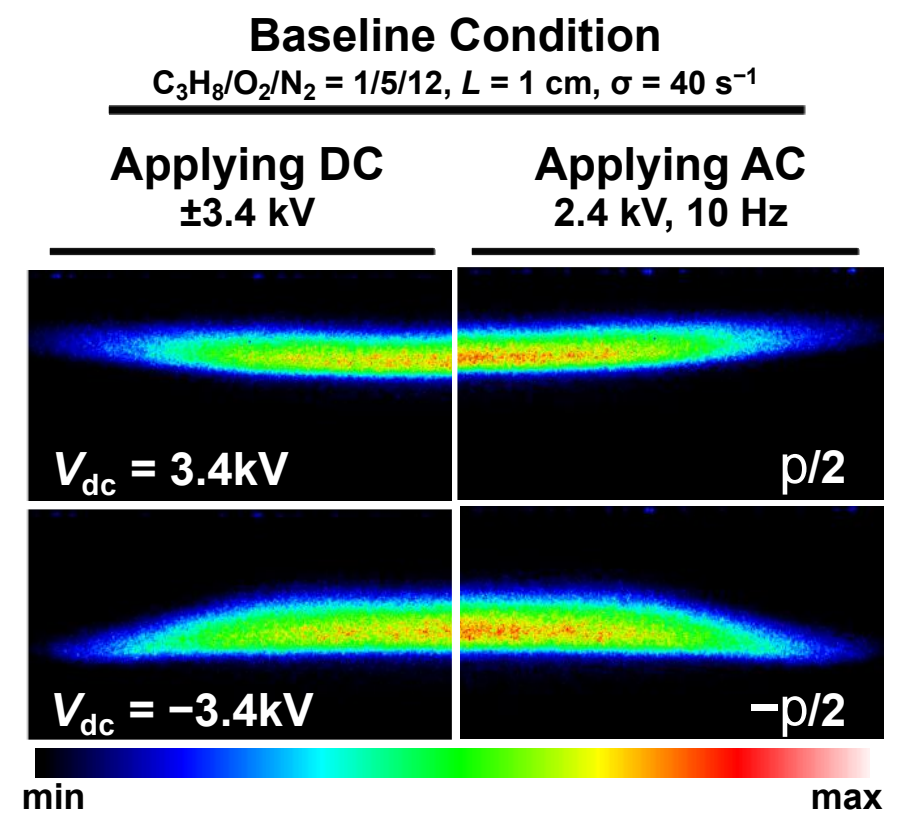

Fig. 3. Comparison of $\mathrm{OH}$ radicals between $\mathrm{DC}$ electric field at $\pm 3.4 \mathrm{kV}$ and $\mathrm{AC}$ electric field at $V_{a c}=2.4 \mathrm{kV}$ with $f_{a c}=10 \mathrm{~Hz}$ on the baseline condition with $X_{\mathrm{F}}=0.111, X_{\mathrm{O} 2}=0.566, U_{\text {jet }}=20$ $\mathrm{cm} / \mathrm{s}$, and $L=1 \mathrm{~cm}\left(\mathrm{C}_{3} \mathrm{H}_{8} / \mathrm{O}_{2} / \mathrm{N}_{2}=1 / 5 / 12\right.$ and $\left.\sigma=40 \mathrm{~s}^{-1}\right)$.

To detail flame behaviors with applied $\mathrm{AC}$, we visualized the $\mathrm{OH}$ radical profiles of an oscillating flame at $f_{a c}=10 \mathrm{~Hz}$ and $V_{a c}=2.4 \mathrm{kV}$ together with the $\mathrm{OH}$ distribution with 
applied DC at $\pm 3.4 \mathrm{kV}$ in the lower nozzle for comparison (Fig. 3). We note that $V_{a c}=2.4 \mathrm{kV}$ (rms) should be considered as $\pm 3.4 \mathrm{kV}$ in peak values. The images on the left of Fig. 3 show half of the flame zone with DC and the images on the right show corresponding AC electric fields with a phase angle of $\pm \pi / 2$ indicating the highest/lowest position from the lower nozzle. The OH PLIF images clearly show that there is minimal difference between the DC cases and the flames at the peak voltages with $\mathrm{AC}$, suggesting that the oscillatory motion of the flame at $f_{a c}=10 \mathrm{~Hz}$ is caused by polarity change. On the other hand, for the flames at higher $f_{a c}$ with negligible flame oscillations, the OH PLIF images with $V_{a c}=2.4 \mathrm{kV}$ shown in Fig. 4 exhibit less-affected $\mathrm{OH}$ profiles as compared with the baseline flame case without an external electric field. These flame responses with increased $f_{a c}$ are discussed below in Section 3.2.

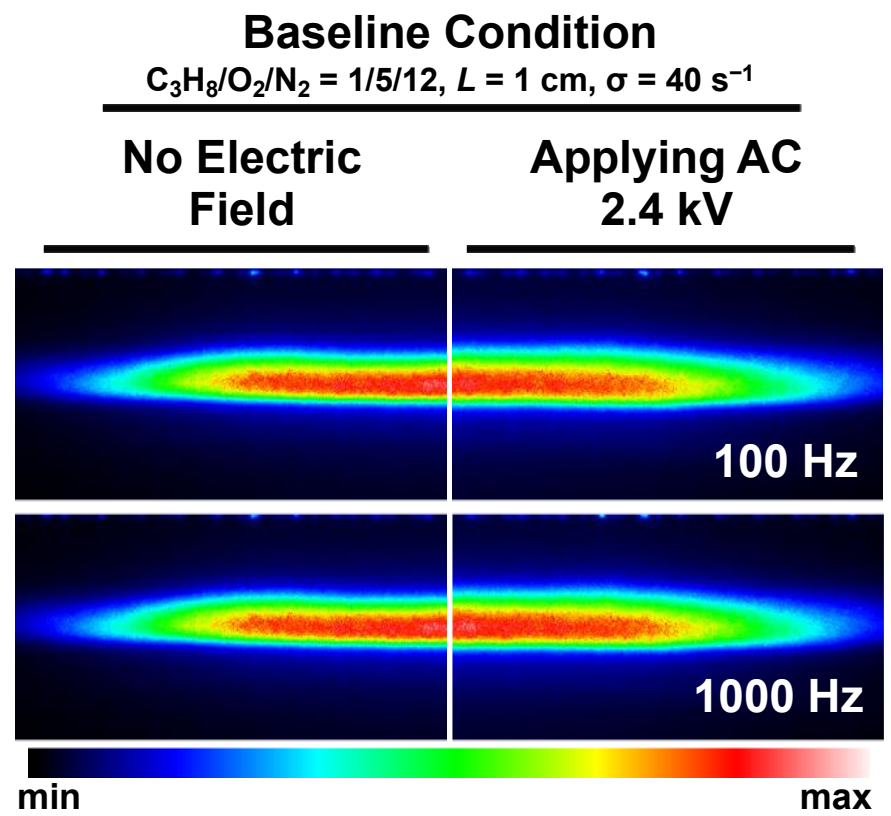

Fig. 4. Comparison of $\mathrm{OH}$ radicals between the flame with no electric field and and $\mathrm{AC}$ electric field at $V_{a c}=2.4 \mathrm{kV}$ with $f_{a c}=100$ and $1000 \mathrm{~Hz}$ on the baseline condition with $X_{\mathrm{F}}=0.111, X_{\mathrm{O} 2}$ $=0.566, U_{\text {jet }}=20 \mathrm{~cm} / \mathrm{s}$, and $L=1 \mathrm{~cm}\left(\mathrm{C}_{3} \mathrm{H}_{8} / \mathrm{O}_{2} / \mathrm{N}_{2}=1 / 5 / 12\right.$ and $\left.\sigma=40 \mathrm{~s}^{-1}\right)$. 
To investigate the connection between observed flame behaviors and the regimes of electrical responses, we measured the electric current by increasing $V_{a c}$ at $f_{a c}=10,100$, and $1000 \mathrm{~Hz}$. Figure 5a compares the current density, which was obtained from the measured rms of the electric current divided by the flame area (the blue luminous area projected on the electrode) at each applied voltage, along with that of the same flame with negative DC electric fields [16]. The DC case shows typical electric current regimes from the subsaturated (a quadratic increase in current with voltage) to the saturated (independent of voltage) regimes, as described detail in [16]. Due to the fluctuating nature of the flame at $f_{a c}$ $=10 \mathrm{~Hz}$, the current density becomes uncertain, which comes from variation in the area of the flame during one cycle rather than from current fluctuation. This follows a reasonably similar trend to that of the negative DC electric field previously reported [16], while a more rapid increase in the current occurs in the sub-saturated regime, particularly for $0.6<V_{a c}<$ $1.0 \mathrm{kV}$. Although unstable flames were observed with applied DC in the range of $1.1<V_{a c}<$ $1.5 \mathrm{kV}$, resulting in indeterminate current [16], no similar unstable behavior was found in the present study with $\mathrm{AC}$ electric field for the tested range of $V_{a c}$ and $f_{a c}$. The unsteady nature of the flame caused by the AC electric field might minimize the instability observed with the applied DC. In conjunction with the $\mathrm{OH}$ images in Fig. 3, the data in Fig. 5 indicate that the overall flame characteristics and the electrical current response when $f_{a c}=10 \mathrm{~Hz}$ were very similar to the case with an applied DC electric field.

As the AC frequency increased (100 and $1000 \mathrm{~Hz}$ ), the increasing rate of current in the sub-saturated regime decreased, similar to the case with the DC electric field. The saturated 
current, which should be proportional to the generation rate of ions and electrons in the flame, dropped significantly, from $\sim 3.5$ to $\sim 1.7 \mu \mathrm{A} / \mathrm{cm}^{2}$, indicating either that the charge generation deteriorated or the number of charges migrating to the electrodes was reduced. Given that the $\mathrm{OH}$ images in Fig. 4 show negligible dependence on the applied AC field, speculating that this drop comes from modified combustion chemistry including ion chemistry (reduction in the charge generation) in the flame may not be a reasonable suggestion.

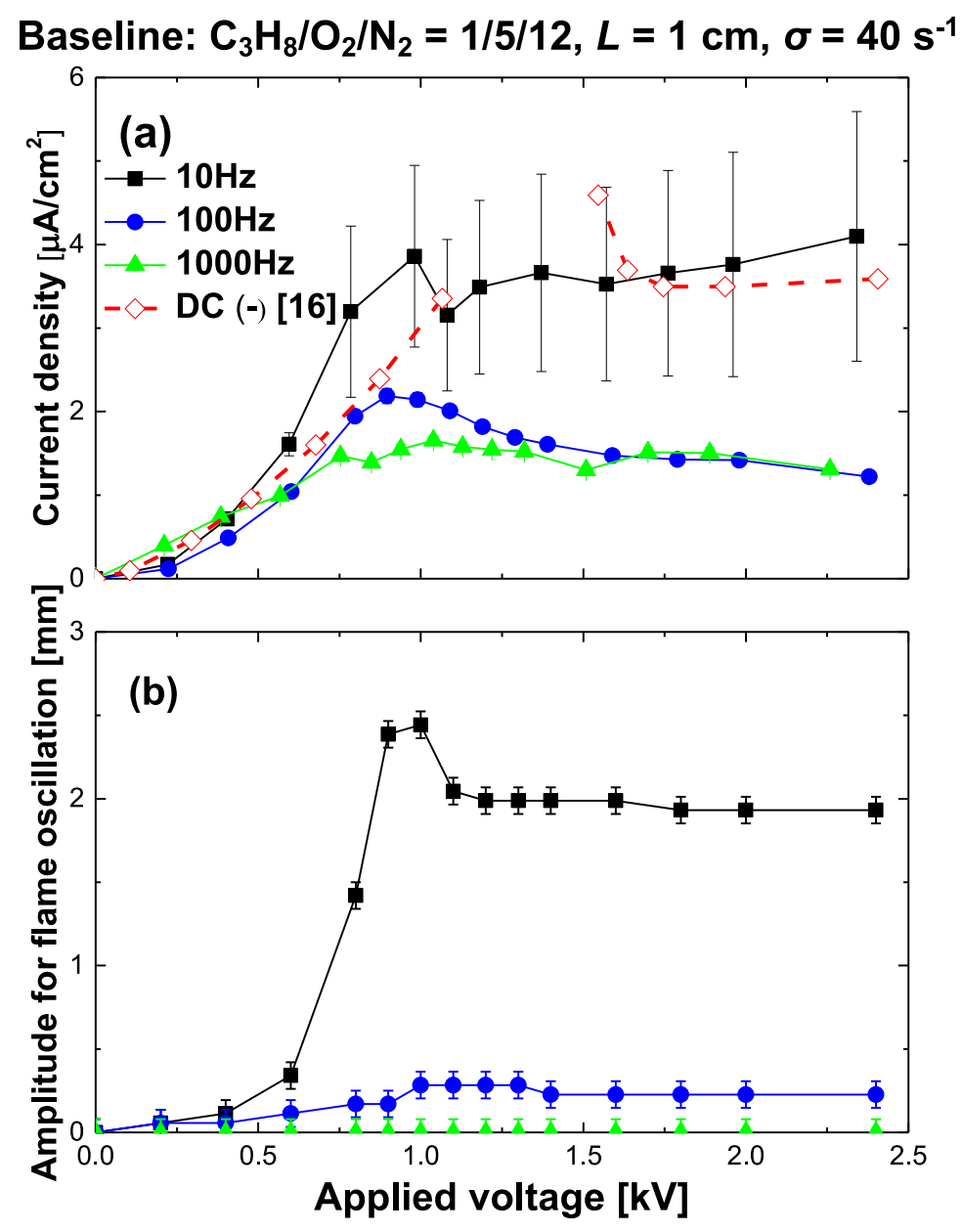

Fig. 5. Response of the (a) electric current density and (b) amplitude of flame oscillation with applied voltage at $f_{a c}=10,100$, and $1000 \mathrm{~Hz}$ on the baseline condition with $X_{F}=0.111, X_{02}=$ 
0.566, $U_{\text {jet }}=20 \mathrm{~cm} / \mathrm{s}$, and $L=1 \mathrm{~cm}\left(\mathrm{C}_{3} \mathrm{H}_{8} / \mathrm{O}_{2} / \mathrm{N}_{2}=1 / 5 / 12\right.$ and $\left.\sigma=40 \mathrm{~s}^{-1}\right)$.

Another possible reason for the lower saturation current with higher AC frequency is the increased recombination rate between positive ions and negative charge carriers neutralizing them, which reduces the total charge in the flow volume. When the AC electric field is applied to the flame, the positive ions and negative charge carriers are separated from the flame toward their respective electrodes during the positive (or negative) phase of the applied voltage. As the phase changes to negative (or positive), the separated positive ions and negative charge carriers existing in the flow volume change their direction of migration, which causes them to collide with each other. Thus, the increased collisions between opposite charge carriers and the resulting charge recombination caused by frequent polarity changes might be responsible for the reduction in the saturation current at higher AC frequencies.

The amplitudes of the oscillating flames (identified as the location of the luminous blue zone as shown in Fig. 2b) with applied AC fields are plotted in Fig. 5b, allowing us to examine the relationship between the flame response and the current response. At $f_{a c}=10 \mathrm{~Hz}$, the amplitude of the flame oscillation was relatively insensitive to low applied voltage $(<0.5$ $\mathrm{kV}$ ); it increased sharply when the applied voltage approached the critical voltage for the current saturation. As the current became saturated over a certain voltage, the amplitude of the flame oscillation also reached a certain level for $f_{a c}=10 \mathrm{~Hz}$. Similar behavior can be observed at $100 \mathrm{~Hz}$, although the amplitude is very small. However, at $f_{a c}=1000 \mathrm{~Hz}$, no significant flame oscillation could be found up to $2.5 \mathrm{kV}$.

The flame oscillation should result from the dynamic response of charged species in the flame zone caused by the electric body force. The non-varying oscillation amplitude in 
the current-saturation regime could be the result of non-varying electric body force to the flow volume. In the saturated regime, since the charged species are drawn away from the flame, the local number density of charged species is controlled by the generation rates and drift velocities of ions and electrons. Because the generation rates can be treated as a characteristic value for a given flame, the number density can be scaled as $n_{i} \sim 1 / v_{i}$, where $i$ is,+- or e, and $v$ is the drift velocity expressed as $v_{i}=K_{i} E$ where $E$ is the electric field intensity. The electric body force for a unit flow volume is expressed as the product of the charge density and the electric field intensity. Thus, $n_{i} E \sim\left(1 / v_{i}\right) E=\left(1 / K_{i} E\right) E=1 / K_{i}$, which indicates that the electric body force in the saturated regime is independent of the electric field intensity. The insensitivity of the flame-oscillation amplitude in the saturated regime to the applied voltage can therefore be qualitatively explained. In the sub-saturated current regime, since the amount of charged species separated from the flame is proportional to the field intensity [15], an increase in the oscillation amplitude with increasing applied voltage is reasonable. However, determination of the location of the flame should be coupled with other constraints, such as transport characteristics in a nonpremixed flame, which determine a flame's position and which are affected by the electric field via ionic wind.

\subsection{Oscillating flame behavior}

The temporal variations in flame positions during one cycle of oscillation for the baseline condition are shown in Fig. 6, where the solid red line indicates the instantaneous voltage patterns (at $V_{a c}=2.0 \mathrm{kV}$ ), which allows for the comparison of phases between the flame oscillation and voltage. In general, the flame is driven by up-and-down movement from 
the polarity change in the applied AC field from the original position of the flame. However, at $f_{a c}=10 \mathrm{~Hz}$ (Fig. 6a) in the sub-saturated regime $\left(V_{a}=0.6\right.$ and $\left.0.9 \mathrm{kV}\right)$, only upwardly displaced flame movements can be observed regardless of the polarity. Two humps can be found at $V_{a c}=0.6$ and $0.9 \mathrm{kV}$, with the second (when the polarity is negative) greater than the first. 


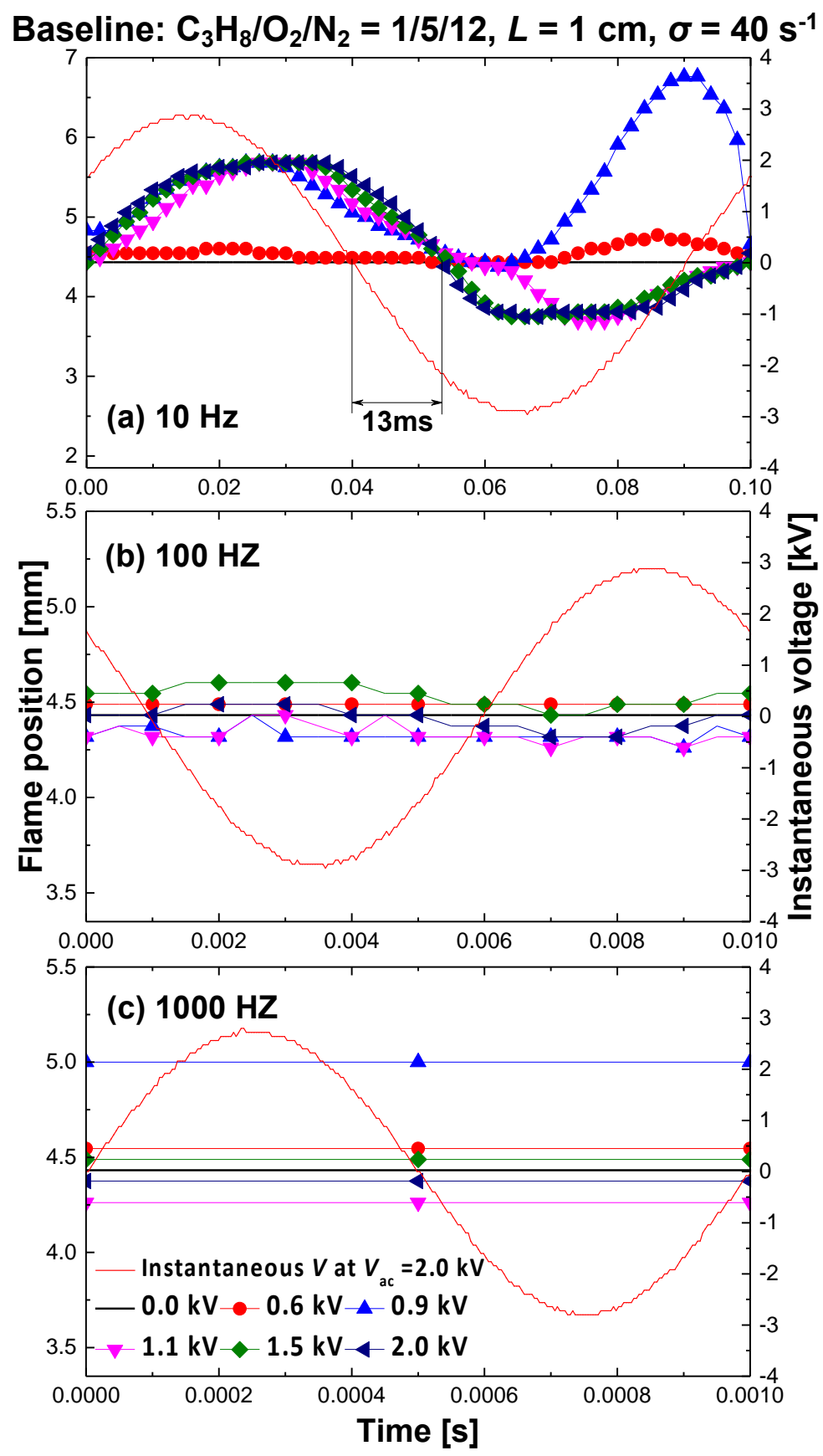

Fig. 6. Temporal flame positions and typical voltage waveforms for various applied voltages at $f_{\mathrm{ac}}=(\mathrm{a}) 10$, (b) 100 , and (c) $1000 \mathrm{~Hz}$ on the baseline condition with $X_{\mathrm{F}}=0.111, X_{\mathrm{O} 2}=0.566, U_{\text {jet }}$ $=20 \mathrm{~cm} / \mathrm{s}$, and $L=1 \mathrm{~cm}\left(\mathrm{C}_{3} \mathrm{H}_{8} / \mathrm{O}_{2} / \mathrm{N}_{2}=1 / 5 / 12\right.$ and $\left.\sigma=40 \mathrm{~s}^{-1}\right)$.

Meanwhile in the saturated regime $\left(V_{a c}=1.1,1.5\right.$, and $\left.2.0 \mathrm{kV}\right)$, the flames swing around 
the original position, but the peaks of positive displacement are greater than those of negative displacement. There are no significant differences between $V_{a c}=1.5$ and $V_{a c}=2.0 \mathrm{kV}$. At $V_{a c}$ $=1.1 \mathrm{kV}$, the only difference is the duration at the reasonably same peak positions as compared to those at higher applied voltages. Once again, this bounded flame trajectory with an applied AC field in the saturated regime (see also Fig. 5b) indicates that the ratio of the electric body force to the flow volume does not vary, although the altered mass and heat transport characteristics with modified flow fields and flame locations due to the applied electric field should play an important role in determining the position of a nonpremixed flame. A detailed explanation for the observed flame behavior is not feasible based only on the experimental observation; a numerical study is needed to identify a clear physicochemical mechanism. There is a phase delay in the flame oscillation from the applied voltage, which is around $\pi / 4(\sim 13 \mathrm{~ms}$ at $10 \mathrm{~Hz})$, which is close to the estimated characteristic collision response time of $\sim 14 \mathrm{~ms}$ as determined by molecular kinetic theory [30].

At $f_{a c}=100 \mathrm{~Hz}$ as shown in Fig. $6 \mathrm{~b}$, a simple but very small $(\sim 0.05 \mathrm{~mm})$ relocation of the flame position toward the upper nozzle occurs at $V_{a c}=0.6 \mathrm{kV}$. With increased $V_{a c}$, oscillations with very small amplitudes $(\sim 0.2 \mathrm{~mm})$ are observed. However, the mean flame position shifts at various AC frequencies; it shifts toward the lower nozzle at $V_{a c}=0.9,1.1$ and $2.0 \mathrm{kV}$ and toward the upper nozzle at $V_{a c}=0.6$ and $1.5 \mathrm{kV}$. Finally, no discernible flame oscillation is observed at $f_{a c}=1000 \mathrm{~Hz}$ (Fig. 6c), while the relocation of the mean flame position is toward the upper nozzle at $0.6,0.9$, and $1.5 \mathrm{kV}$ and toward the lower nozzle at 1.1 and $2.0 \mathrm{kV}$ unlike the cases of $100 \mathrm{~Hz}$. The reasons for these inconsistent mean flame positions with applied AC electric fields are not clear. These observations indicate the 
difficulties experienced in conceptual modeling approaches, because a dynamic system (described as an electric body force acting on the flow volume) has varying mass and ion number density over time, and its motion is constrained by the transport properties (i.e., mass and heat) in nonpremixed flames. We note that a recent model of flame behavior with an applied AC electric field [31] may require modification to account for our present observations.

Because of the steady oscillating motion in the saturated regime regardless of $V_{a c}$ (i.e., a constant flame oscillation amplitude at a given frequency as in Fig. 5b), we investigated the oscillating amplitudes of the various flames by varying $V_{a c}$ and $f_{a c}$ (Table 1). At $L=1$ and $2 \mathrm{~cm}$, the required applied voltages were 2.4 and $4.8 \mathrm{kV}$, respectively, allowing us to apply the same external field intensities $\left(E=V_{a c} L\right)$ and ensuring that the flames were in the saturated regime.

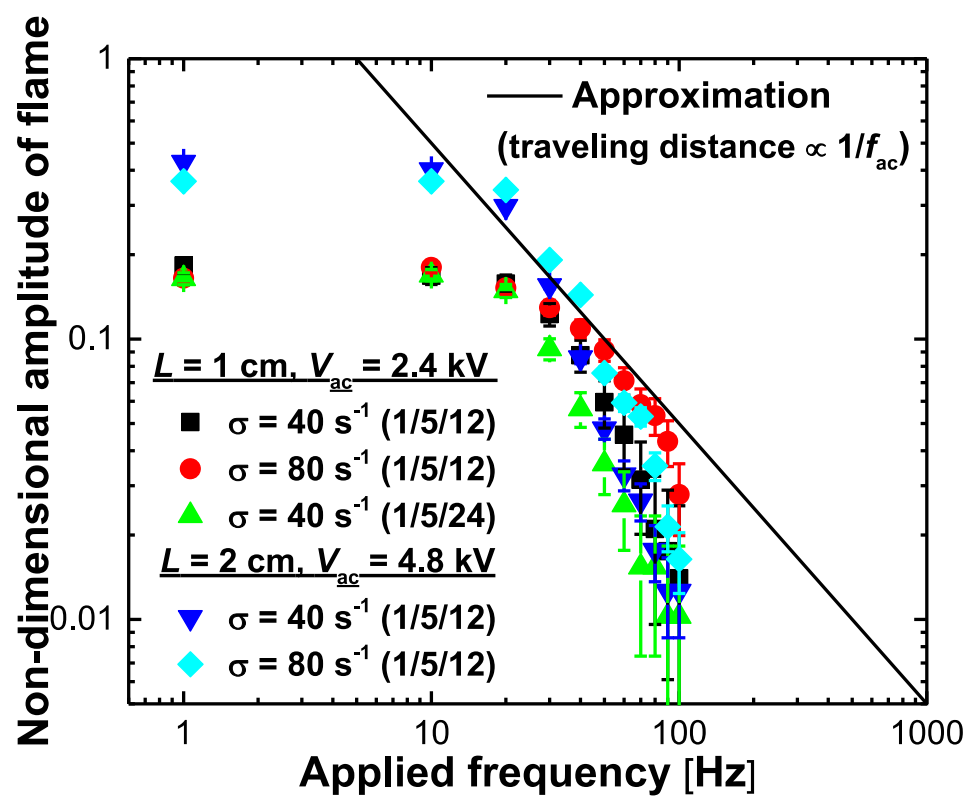

Fig. 7. Non-dimensional amplitude of flame oscillation using the gap distance $L$ in relation to applied frequency for various flame conditions as in Table 1. 
Figure 7 shows non-dimensional oscillation amplitudes divided by each $L$ with the applied frequency given in log scales. Assuming that a dynamic response of the flame to the electric field may result in a constant mean displacement speed of a flame during a cycle ( similar to the terminal velocity of charged species with ionic wind $\left(\sim K_{i} E\right)$ ), the amplitude of the flame oscillation (the traveling distance of the flame) should be proportional to the duration of a cycle $\left(f_{a c}^{-1}\right)$. Thus, the solid line in Fig. 7 indicates the functional relation of $y$ $\sim x^{-1}$ as the predicted trend of the amplitude with a constant mean flame displacement speed.

As a result, the dynamic response of the nonpremixed flames can be divided into two regimes: 1) the transport limit regime and 2) the oscillating decaying regime. As previously mentioned, the peak location of an oscillating motion with low frequency (e.g., $f_{a c}=10 \mathrm{~Hz}$ ) is the same as the displaced location with the DC electric field (Fig. 3). Such a limited amplitude is maintained up to $\sim 20 \mathrm{~Hz}$. The non-dimensional amplitude in this plateau with $L$ $=1 \mathrm{~cm}$ is around 0.2 , but it reaches $\sim 0.4$ at $L=2 \mathrm{~cm}$, with two distinctive values categorized by the gap distance regardless of the strain rate and nitrogen dilution. Thus, the limits of the flame oscillation in this regime are closely related to the geometrical configuration and to the related transport characteristics that determine the location of the nonpremixed flame.

When the AC frequency increases beyond this transport limit regime, the nondimensional flame amplitude begins to decrease as expected. However, all tested conditions exhibited much faster decay in amplitude than determined by the reference approximation line, indicating that the cyclic mean flame displacement speed decreases as the frequency increases, resulting in a shorter traveling distance. This behavior can be attributed to the lower 
electric body force due to decreased saturation current for increased $f_{a c}$ as shown in Fig. 5a, or it may be governed by a mechanism similar to a simple dynamic oscillatory system (mass, damper, and spring) in which the response to external harmonic excitation similarly decays with increased frequency depending on the ratios of these three factors.

It is interesting to recall a previous study done by Egolfopoulos and Campbell [32] for a non-premixed flame's response to the unsteady fluctuations of velocity, reactant concentration, and temperature at the exits of a counterflow burner. Based on the analogy with Stokes' second problem, they found that a Stokes' parameter defined as $(\omega / 2 \sigma)^{1 / 2}$, where $\omega=2 \pi f$, could characterize a oscillating behavior of the flame temperature [32] showing rapid decays of perturbed temperature when $(\omega / 2 \sigma)^{1 / 2} \sim O(1)$.

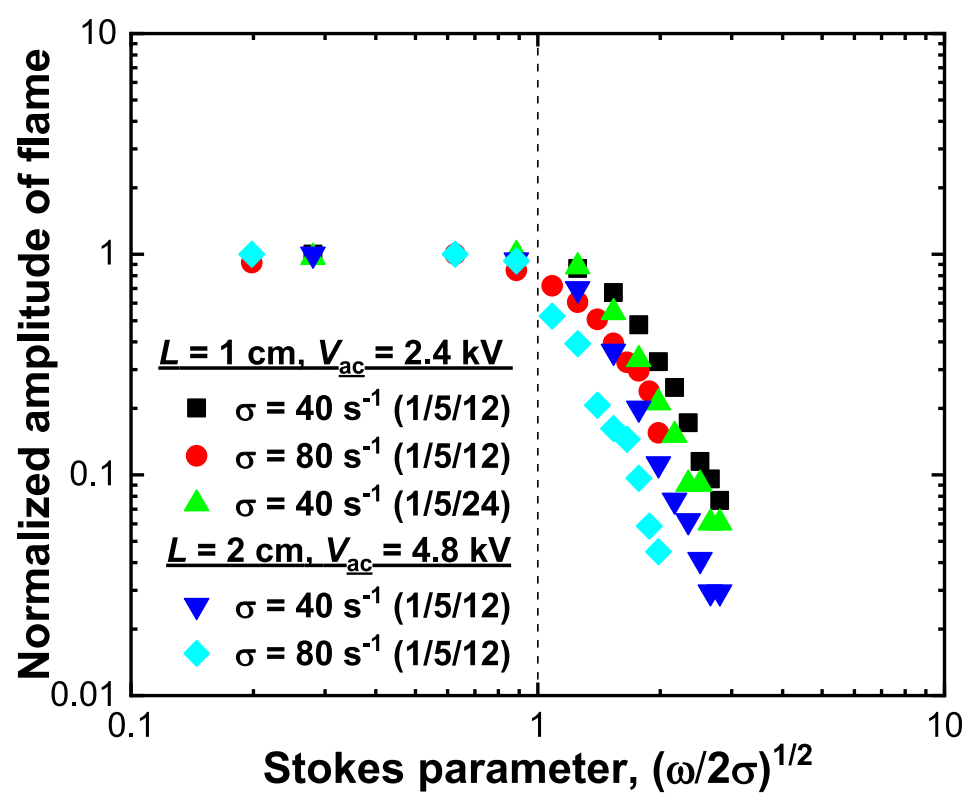

Fig. 8. Replotted result of Fig. 7 in terms of the Stokes' parameter $(\omega / 2 \sigma)^{1 / 2}$ and the normalized amplitude of flame by the maximum oscillation amplitude for a given flame, where $\omega=2 \pi f_{a c}$. 
In this regard, the data in Fig. 7 were replotted in terms of the Stokes' parameter and a normalized flame amplitude (which is different from the non-dimensional flame amplitude) using maximum amplitude of each flow condition. As shown in Fig. 8, the flame oscillations also show abrupt attenuation at $(\omega / 2 \sigma)^{1 / 2} \sim O(1)$, but the Stokes' parameter does not seem to be an appropriate one to scale the behavior during the attenuation for higher Stokes' parameter. This may be attributed to that the electric fields directly affect the flame behavior through the electric body force acting on the entire flow volume, while the fluctuations of velocity, reactant concentration, and temperature at burner exits need to propagate to a flame location similar to the Stokes' second problem. This point will be elaborated in the next section mentioning the effect of electric fields on flow fields.

\subsection{Flow visualization and bidirectional ionic wind}

In a previous study using applied DC fields [16], a bidirectional ionic wind was generated mostly in the saturated regime. This convection caused significant modification in the flow, leading to a double-stagnant flow configuration. We used high-speed visualization of the flow field using Mie scattering from the seed particles [16] to clarify the effect of an $\mathrm{AC}$ electric field on the modification of the flow field in the counterflow configuration (Supplementary Movies 1-4).

Supplementary Movie 2 shows a typical variation in the flow field with an applied AC electric field (at $V_{a c}=2.4 \mathrm{kV}$ and $f_{a c}=10 \mathrm{~Hz}$ ) as compared to the baseline condition without the AC field (Supplementary Movie 1). The main jet streams from both nozzles oscillate in accordance with the direction of the electric field, showing synchronized frequency $(10 \mathrm{~Hz})$. 
The localized, non-uniform particle distributions near the nozzle exits are due to the perforated plates. Figure 9 shows instantaneous flow patterns for $V_{a c}=2.4 \mathrm{kV}$ and $f_{a c}=10$ $\mathrm{Hz}$ during one cycle of ionic wind oscillation (from $-\pi$ to $\pi$ ). As reported in our previous study [16], the edges of two groups of scattered particles at the boundaries between the central dark zone indicate new stagnation planes, which are created in response to the bidirectional ionic wind blowing from the flame toward both upper and lower electrodes (nozzles). The phase in the figure shows that the minimum (maximum) dark zone thickness with 0 and $\pm \pi( \pm \pi / 2)$. When the dark zone is minimized, the flame (indicated as the white lines in Fig. 9) sits near the center of the gap, whereas when the dark zone is maximized, the flame moves toward the upper and lower nozzles due to the change in polarity during a cycle. 


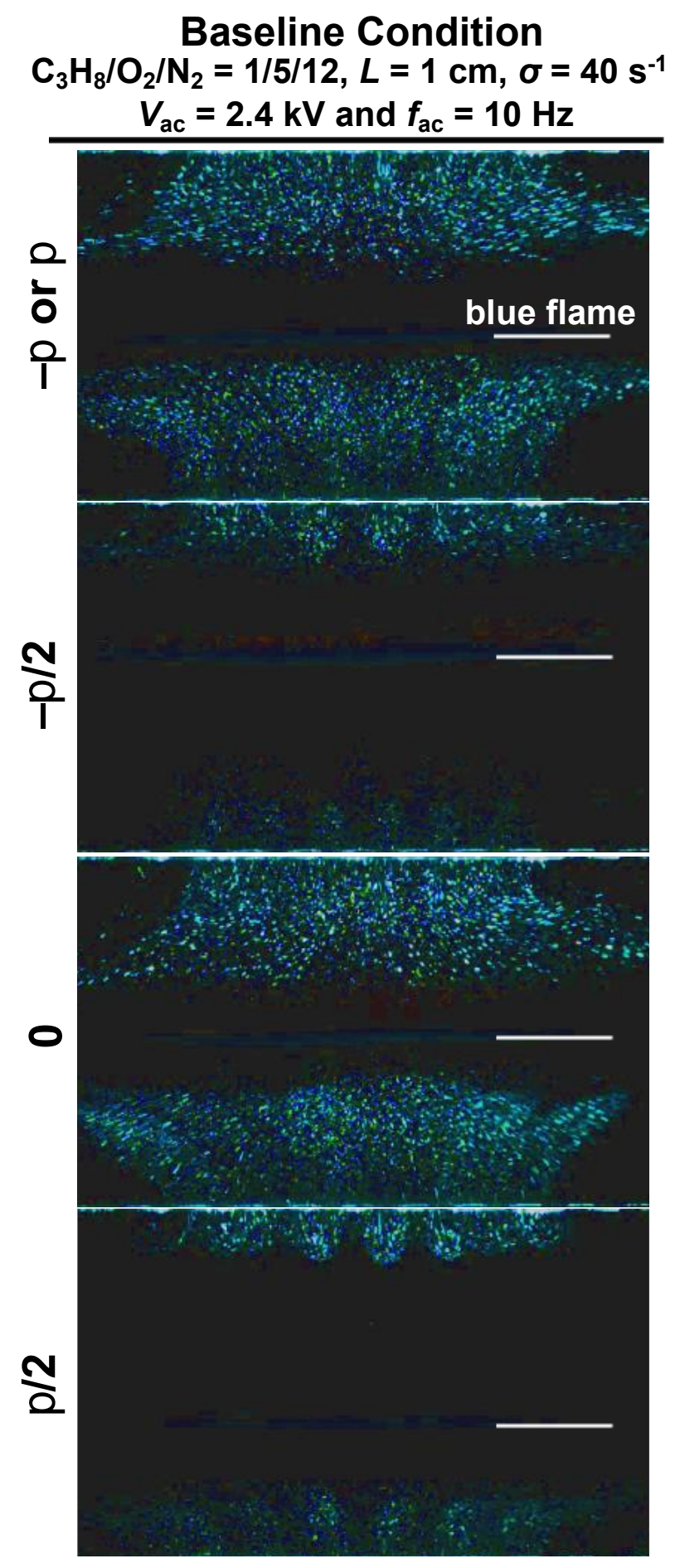

Fig. 9. A temporal variation in the dark zone for the baseline condition $\left(X_{\mathrm{F}}=0.111, X_{\mathrm{O} 2}=0.566\right.$, $U_{\text {jet }}=20 \mathrm{~cm} / \mathrm{s}$, and $L=1 \mathrm{~cm}$ ) at $V_{a c}=2.4 \mathrm{kV}$ and $f_{a c}=10 \mathrm{~Hz}$. The white line in each image indicates the location of a blue flame. 
Figure 10 shows the pathlines of the seeding particles ejected from the nozzles at $f_{a c}=$ (a) 100 and (b) $1000 \mathrm{~Hz}$ with selected $V_{a c}$ for the baseline condition ( $0.1 \mathrm{~s}$ exposure time). In the flame without an applied AC field, reddish luminosity caused by radiation from the seeding particles passing through a high-temperature zone appears at the stagnation plane. This suggests that the main heat release reaction occurs at the stagnation plane because we designed the stoichiometric location to be there $\left(Z_{\mathrm{st}}=0.5\right)$. The luminous blue zone is located slightly into the fuel stream (Supplementary Movie 1). The overall flow fields at both frequencies are not affected when $V_{a c}=0.7 \mathrm{kV}$, implying that the relatively low voltage in the sub-saturated regime has minimal impact on the flame or the flow, which is consistent with observations of an applied DC field [16]. 

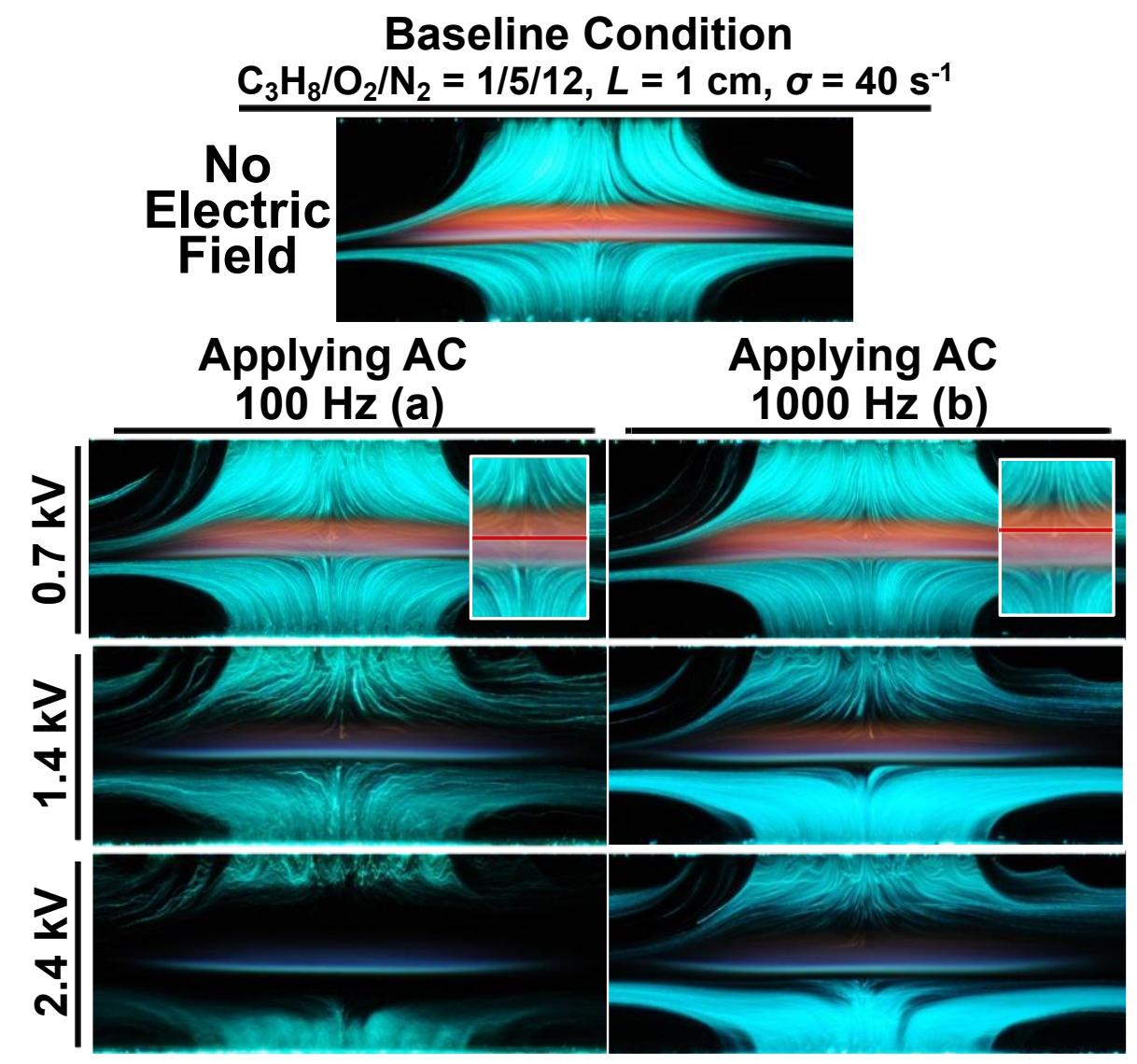

Fig. 10. Flow visualization for selected applied voltages at $f_{a c}=(a) 100$ and (b) $1000 \mathrm{~Hz}$ on the baseline condition with $X_{\mathrm{F}}=0.111, X_{\mathrm{O} 2}=0.566, U_{\text {jet }}=20 \mathrm{~cm} / \mathrm{s}$, and $L=1 \mathrm{~cm}\left(\mathrm{C}_{3} \mathrm{H}_{8} / \mathrm{O}_{2} / \mathrm{N}_{2}=\right.$ $1 / 5 / 12$ and $\sigma=40 \mathrm{~s}^{-1}$ ).

However, at $V_{a c}=1.4 \mathrm{kV}$ in the saturated regime, a drastic modification of the flow field due to the applied AC field creates double-stagnation planes at both frequencies, resulting from the bidirectional ionic wind. The dark zone in proximity of the flame exhibits rather steady behavior at these frequencies. When the applied voltage is increased to $V_{a c}=$ $2.4 \mathrm{kV}$, the dark zones become thicker because the intensity of the ionic wind is proportional to the applied voltage $\left(\sim K_{i} E\right)$. The broadening of the dark zone at $1000 \mathrm{~Hz}$ is weaker than that at $100 \mathrm{~Hz}$, which may be the result of increased charge neutralization caused by the higher rate of polarity change and the characteristic flow induction time with molecular 
collisions [33].

At $f_{a c}=100 \mathrm{~Hz}$ (Supplementary Movie 3), a pulsating oscillation of the free stream, synchronized with $f_{a c}$ with small variation in the dark zone, is observed. On the other hand, no discernable oscillation in the dark zone is found at $f_{a c}=1000 \mathrm{~Hz}$ (Supplementary Movie 4). Even though the flame at $1000 \mathrm{~Hz}$ remains visibly steady (Fig. 6c), the ionic wind blows from the flame to the electrodes and exhibits drastic modification of the flow fields. This result is consistent with a previous study in an axisymmetric jet configuration with traverse AC fields [24].

To understand the dependence of bidirectional ionic wind on $f_{a c}$, we introduced a nondimensional dark zone thickness normalized by the gap distance, which is indicative of the influence of the bidirectional ionic wind for various $f_{a c}$ in selected flames at different $L$ and $\sigma$ at $E=2.4 \mathrm{kV} / \mathrm{cm}\left(V_{a c}=2.4 \mathrm{kV}\right.$ for $L=1 \mathrm{~cm}, V_{a c}=4.8 \mathrm{kV}$ for $\left.L=2 \mathrm{~cm}\right)$, as shown in Fig. 11. At low $f_{a c}$ with an oscillating dark zone $(<200 \mathrm{~Hz})$, only the maximum thickness is selected for the sake of simplicity. Unlike the flame's oscillatory motion, the dark zone thickness decreases slowly with increasing applied frequency. Therefore, even though the visible flame motion is steady at higher $\mathrm{AC}$ frequencies, it is not practical to assume that the effect of the applied AC fields on the ionic wind is negligible. 


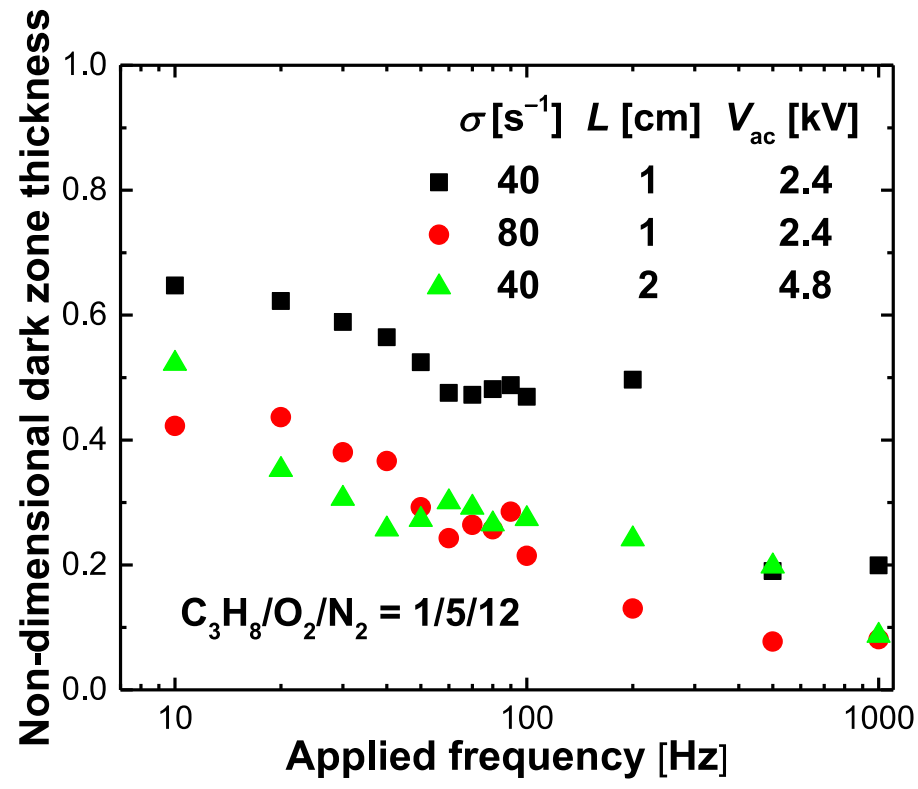

Fig. 11. Non-dimensional dark zone thickness using the gap distance $L$ in relation to applied frequency for the overall mixture condition of $\mathrm{C}_{3} \mathrm{H}_{8} / \mathrm{O}_{2} / \mathrm{N}_{2}=1 / 5 / 12\left(X_{\mathrm{F}}=0.111\right.$ and $\left.X_{02}=0.566\right)$. External AC field intensity was maintained at $E=2.4 \mathrm{kV} / \mathrm{cm} ; V_{a c}=2.4 \mathrm{kV}$ at $L=1 \mathrm{~cm}$ and $V_{a c}=$ $4.8 \mathrm{kV}$ at $L=2 \mathrm{~cm}$.

Non-dimensional dark zone thicknesses at $L=2 \mathrm{~cm}$ with $\sigma=40 \mathrm{~s}^{-1}$ agreed well with thicknesses at $L=1 \mathrm{~cm}$ with $\sigma=80 \mathrm{~s}^{-1}$, indicating a parametric similarity in the jet velocity $\left(U_{\text {jet }}=40 \mathrm{~cm} / \mathrm{s}\right)$. A new stagnation plane due to the ionic wind should be determined by the momentum theorem between the ionic wind and the jet flow, and the ionic wind velocity should be similar among the flames tested due to identical mixture composition and electric field intensity. Thus, the dark zone thickness, which is a measure of the distance separating two new stagnation planes, should be related to the jet velocity rather than strain rate.

We replotted Fig. 11 in terms of a normalized dark zone thickness and the Stokes' parameter (Fig. 12) to show a different nature of flow fields' responses to the electric fields. Once again, the first impact of external electric fields on a flame is a charge separation from 
the flame. Thus, the modification of corresponding flow field is a result of electric body force due to the charge separation. In this light, measuring the dark zone thickness surrounding the flame is a kind of investigating the fluctuating source, therefore, we could not find an analogy with Stokes' second problem as shown in Fig. 12, which illustrates significantly slower attenuation of the dark zone thickness for increased Stokes' parameter (cf. Fig. 8). However, since the flame's response is caused by the modified flow field and altered transport processes from the upstream, the flame's response should show an analogous behavior with Stokes' second problem due to the attenuation of upstream fluctuations with higher frequency characterized by the Stokes' parameter. This was shown in Fig. 8 illustrating the abrupt attenuation of the flame's oscillation when $(\omega / 2 \sigma)^{1 / 2}=\left(\pi f_{a c} / \sigma\right)^{1 / 2} \sim O(1)$.

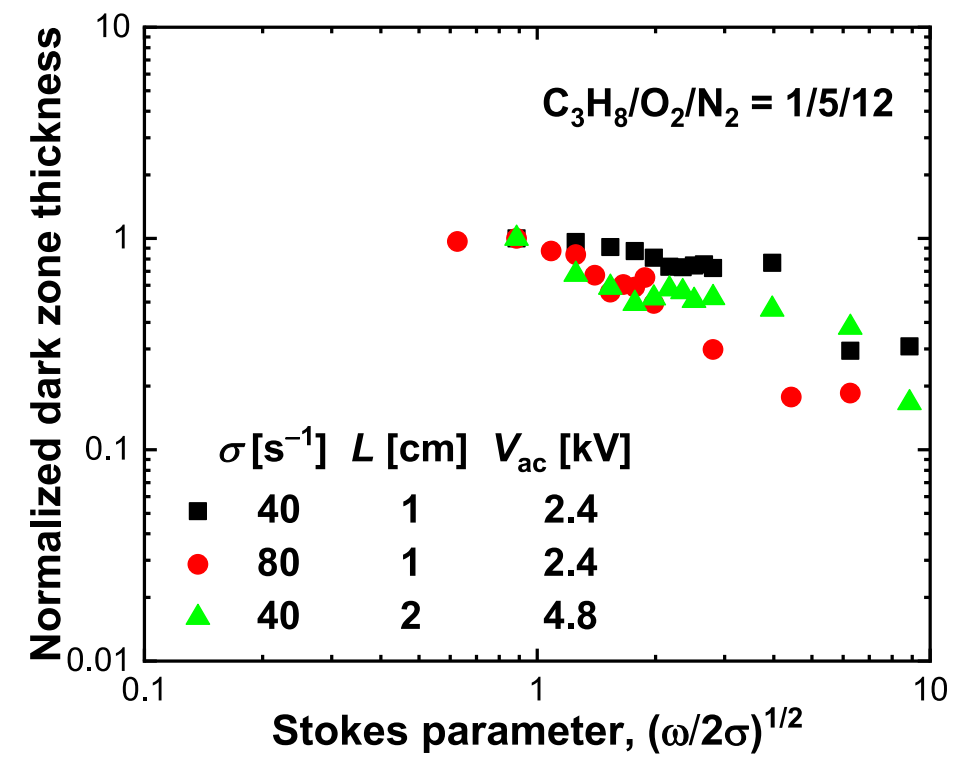

Fig. 12. Replotted result of Fig. 11 in terms of the Stokes' parameter $(\omega / 2 \sigma)^{1 / 2}$ and the normalized dark zone thickness by the maximum thickness for a given flame, where $\omega=2 \pi f_{a c}$. The overall mixture condition of $\mathrm{C}_{3} \mathrm{H}_{8} / \mathrm{O}_{2} / \mathrm{N}_{2}=1 / 5 / 12\left(X_{\mathrm{F}}=0.111\right.$ and $\left.X_{\mathrm{O} 2}=0.566\right)$. External AC field intensity was maintained at $E=2.4 \mathrm{kV} / \mathrm{cm} ; V_{a c}=2.4 \mathrm{kV}$ at $L=1 \mathrm{~cm}$ and $V_{a c}=4.8 \mathrm{kV}$ at $L=2 \mathrm{~cm}$. For easy comparison with the flame oscillation, the domain is intentionally set to be the same with Fig. 8. 


\section{Concluding Remarks}

We experimentally investigated the dynamic response of nonpremixed flames and their voltage-current characteristics and modified flow fields with applied AC fields in a counterflow burner. Our results indicate that the flame response is divided into two regimes: i) a plateau of flame oscillation amplitude at lower frequencies $(<\sim 20 \mathrm{~Hz})$, which seems to be controlled by geometrical parameters affecting transport parameters of the flame and ii) a quickly decaying flame amplitude with increased AC frequency, which might be limited by the traveling distance of the flame during one cycle of applied AC. The reduced saturation current as the AC frequency increases could be a result of increased neutralization due to frequent cross-collisions between positive and negative charge carriers caused by polarity changes. This reduced saturation current could also be the reason for the further decreased flame amplitude with increased AC frequency, since it leads to a decrease in the charge density resulting in a reduced electric body force.

Although we observed visibly steady flames when the applied AC field was greater than $200 \mathrm{~Hz}$, the thickness of the dark zone, which was created as a result of the ionic wind blowing from the flame toward both electrodes, decreased rather slowly, and it could be observed up to $1 \mathrm{kHz}$ AC frequency. The effects of ionic wind on flames are not negligible even at high $\mathrm{AC}$ frequencies with visibly steady flames.

The primary impact of an electric field on a flame is the charged species movement in the respective direction (represented by the V-I characteristics), resulting in local space 
charges that create an electric body force in the flow volume. This causes ionic wind and flame relocation, which is determined by the modified flow field and altered transport parameters, depending on a flame type (premixed or nonpremixed). For a thorough explanation of flame and flow dynamics, conceptual models, comprehensive multidimensional simulations that include ion-chemistry and electric body force, and the accumulation of fundamental experimental data for model validation, are all needed.

\section{Acknowledgement}

The research reported in this publication was supported by Competitive Research Funding from King Abdullah University of Science and Technology (KAUST).

\section{References}

[1] D.G. Park, B.C. Choi, M.S. Cha, S.H. Chung, Soot Reduction Under DC Electric Fields in Counterflow Non-Premixed Laminar Ethylene Flames, Combust. Sci. Technol. 186 (2014) 644-656.

[2] M.S. Cha, S.M. Lee, K.T. Kim, S.H. Chung, Soot suppression by nonthermal plasma in coflow jet diffusion flames using a dielectric barrier discharge, Combust. Flame 141 (2005) 438-447.

[3] E. Place, F. Weinberg, Electrical control of flame carbon, Proc. Royal Soc. Lond. Ser. A. Mathematical and Physical Sciences 289 (1966) 192-205.

[4] M. Saito, T. Arai, M. Arai, Control of soot emitted from acetylene diffusion flames by applying an electric field, Combust. Flame 119 (1999) 356-366.

[5] D.R. Hardesty, F.J. Weinberg, Electrical control of particulate pollutants from flames, Symp. (Int.) Combust. 14 (1973) 907-918.

[6] M.S. Cha, Y. Lee, Premixed Combustion Under Electric Field in a Constant Volume Chamber, IEEE Trans. Plasma Sci. 40 (2012) 3131-3138.

[7] S.H. Won, S.K. Ryu, M.K. Kim, M.S. Cha, S.H. Chung, Effect of electric fields on the propagation speed of tribrachial flames in coflow jets, Combust. Flame 152 (2008) 496-506. 
[8] R.J. Bowser, F.J. Weinberg, The effect of direct electric fields on normal burning velocity, Combust. Flame 18 (1972) 296-300.

[9] E. Guenault, R. Wheeler, 423. The propagation of flame in electric fields. Part II. The effects of transverse fields, J. Chem. Soc. (Resumed) (1932) 2788-2793.

[10] H.C. Jaggers, A. von Engel, The effect of electric fields on the burning velocity of various flames, Combust. Flame 16 (1971) 275-285.

[11] M. Belhi, P. Domingo, P. Vervisch, Direct numerical simulation of the effect of an electric field on flame stability, Combust. Flame 157 (2010) 2286-2297.

[12] M.K. Kim, S.H. Chung, H.H. Kim, Effect of AC electric fields on the stabilization of premixed bunsen flames, Proc. Combust. Inst. 33 (2011) 1137-1144.

[13] M.K. Kim, S.K. Ryu, S.H. Won, S.H. Chung, Electric fields effect on liftoff and blowoff of nonpremixed laminar jet flames in a coflow, Combust. Flame 157 (2010) 17-24.

[14] R. Noorani, R. Holmes, Effects of electric fields on the blowoff limits of a methane-air flame, AIAA J. 23 (1985) 1452-1454.

[15] A.M. Drews, L. Cademartiri, M.L. Chemama, M.P. Brenner, G.M. Whitesides, K.J.M. Bishop, ac electric fields drive steady flows in flames, Phys. Rev. E 86 (2012) 036314.

[16] D.G. Park, S.H. Chung, M.S. Cha, Bidirectional ionic wind in nonpremixed counterflow flames with DC electric fields, Combust. Flame 168 (2016) 138-146.

[17] S. Marcum, B. Ganguly, Electric-field-induced flame speed modification, Combust. Flame 143 (2005) 27-36.

[18] J.M. Goodings, D.K. Bohme, C.-W. Ng, Detailed ion chemistry in methane-oxygen flames. I. Positive ions, Combust. Flame 36 (1979) 27-43.

[19] J.M. Goodings, D.K. Bohme, C.-W. Ng, Detailed ion chemistry in methane-oxygen flames. II. Negative ions, Combust. Flame 36 (1979) 45-62.

[20] A.B. Fialkov, Investigations on ions in flames, Prog. Energy Combust. Sci. 23 (1997) 399-528.

[21] F. Carleton, F. Weinberg, Electric field-induced flame convection in the absence of gravity, Nature 330 (1987) 635-636.

[22] J. Lawton, F.J. Weinberg, Electrical aspects of combustion, Clarendon Press Oxford 1969.

[23] J. Lawton, P.J. Mayo, F.J. Weinberg, Electrical Control of Gas Flows in Combustion Processes, Proc. Royal Soc. A303 (1968) 275-298.

[24] D.G. Park, S.H. Chung, M.S. Cha, Visualization of ionic wind in laminar jet flames, Combust. Flame 173 (2016) 114-122.

[25] M.-V. Tran, M.S. Cha, Propagating nonpremixed edge-flames in a counterflow, annular slot burner under DC electric fields, Combust. Flame 184 (2017) 246-248.

[26] M.-V. Tran, M.S. Cha, Time evolution of propagating nonpremixed flames in a counterflow, annular slot burner under AC electric fields, Proc. Combust. Inst. 36 (2017) 
1421-1430.

[27] S.H. Yoon, B. Seo, J. Park, S.H. Chung, M.S. Cha, Edge flame propagation via parallel electric fields in nonpremixed coflow jets, Proc. Combust. Inst. 37 (2018) doi.org/10.1016/j.proci.2018.06.026.

[28] M.S. Cha, P.D. Ronney, Propagation rates of nonpremixed edge flames, Combust. Flame 146 (2006) 312-328.

[29] Y. Xiong, D.G. Park, B.J. Lee, S.H. Chung, M.S. Cha, DC field response of onedimensional flames using an ionized layer model, Combust. Flame 163 (2016) 317325 .

[30] M. Kono, F.B. Carleton, A.R. Jones, F.J. Weinberg, The effect of nonsteady electric fields on sooting flames, Combust. Flame 78 (1989) 357-364.

[31] C. Guerra-Garcia, M. Martinez-Sanchez, Counterflow nonpremixed flame DC displacement under AC electric field, Combust. Flame 162 (2015) 4254-4263.

[32] F.N. Egolfopoulos, C.S. Campbell, Unsteady counterflowing strained diffusion flames: diffusion-limited frequency response, J. Fluid Mech. 318 (1994) 1-29.

[33] M.K. Kim, S.H. Chung, H.H. Kim, Effect of electric fields on the stabilization of premixed laminar bunsen flames at low $\mathrm{AC}$ frequency: Bi-ionic wind effect, Combust. Flame 159 (2012) 1151-1159. 


\section{List of Table, Figures, and Supplementary Movies}

Table 1. Experimental conditions.

Figure 1. Schematic of the experimental setup.

Figure 2. Typical flames with the baseline condition: $X_{\mathrm{F}}=0.111, X_{\mathrm{O} 2}=0.566, U_{\text {jet }}=20 \mathrm{~cm} / \mathrm{s}$, and $L=1 \mathrm{~cm}\left(\mathrm{C}_{3} \mathrm{H}_{8} / \mathrm{O}_{2} / \mathrm{N}_{2}=1 / 5 / 12\right.$ and $\left.\sigma=40 \mathrm{~s}^{-1}\right)$. (a) without an applied electric field, and (b) $f_{a c}=10$, (c) 100 , and (d) $1000 \mathrm{~Hz}$ at fixed $V_{a c}=2.0 \mathrm{kV}$.

Figure 3. Comparison of $\mathrm{OH}$ radicals between $\mathrm{DC}$ electric field at $\pm 3.4 \mathrm{kV}$ and $\mathrm{AC}$ electric field at $V_{a c}=2.4 \mathrm{kV}$ with $f_{a c}=10 \mathrm{~Hz}$ on the baseline condition with $X_{\mathrm{F}}=0.111, X_{\mathrm{O} 2}$ $=0.566, U_{\text {jet }}=20 \mathrm{~cm} / \mathrm{s}$, and $L=1 \mathrm{~cm}\left(\mathrm{C}_{3} \mathrm{H}_{8} / \mathrm{O}_{2} / \mathrm{N}_{2}=1 / 5 / 12\right.$ and $\left.\sigma=40 \mathrm{~s}^{-1}\right)$.

Figure 4. Comparison of $\mathrm{OH}$ radicals between the flame with no electric field and and $\mathrm{AC}$ electric field at $V_{a c}=2.4 \mathrm{kV}$ with $f_{a c}=100$ and $1000 \mathrm{~Hz}$ on the baseline condition with $X_{\mathrm{F}}=0.111, X_{\mathrm{O} 2}=0.566, U_{\text {jet }}=20 \mathrm{~cm} / \mathrm{s}$, and $L=1 \mathrm{~cm}\left(\mathrm{C}_{3} \mathrm{H}_{8} / \mathrm{O}_{2} / \mathrm{N}_{2}=1 / 5 / 12\right.$ and $\left.\sigma=40 \mathrm{~s}^{-1}\right)$.

Figure 5. Response of the (a) electric current density and (b) amplitude of flame oscillation with applied voltage at $f_{a c}=10,100$, and $1000 \mathrm{~Hz}$ on the baseline condition with $X_{\mathrm{F}}$ $=0.111, X_{\mathrm{O} 2}=0.566, U_{\text {jet }}=20 \mathrm{~cm} / \mathrm{s}$, and $L=1 \mathrm{~cm}\left(\mathrm{C}_{3} \mathrm{H}_{8} / \mathrm{O}_{2} / \mathrm{N}_{2}=1 / 5 / 12\right.$ and $\sigma=40$ $\left.\mathrm{s}^{-1}\right)$.

Figure 6. Temporal flame positions and typical voltage waveforms for various applied voltages at $f_{a c}=$ (a) 10 , (b) 100 , and (c) $1000 \mathrm{~Hz}$ on the baseline condition with $X_{\mathrm{F}}=$ $0.111, X_{\mathrm{O} 2}=0.566, U_{\text {jet }}=20 \mathrm{~cm} / \mathrm{s}$, and $L=1 \mathrm{~cm}\left(\mathrm{C}_{3} \mathrm{H}_{8} / \mathrm{O}_{2} / \mathrm{N}_{2}=1 / 5 / 12\right.$ and $\sigma=40 \mathrm{~s}^{-}$ $\left.{ }^{1}\right)$.

Figure 7. Non-dimensional amplitude of flame oscillation using the gap distance L in relation to applied frequency for various flame conditions as in Table 1.

Figure 8. Replotted result of Fig. 7 in terms of the Stokes' parameter $(\omega / 2 \sigma)^{1 / 2}$ and the normalized amplitude of flame by the maximum oscillation amplitude for a given flame, where $\omega=2 \pi f_{a c}$.

Figure 9. A temporal variation in the dark zone for the baseline condition $\left(X_{\mathrm{F}}=0.111, X_{\mathrm{O} 2}=\right.$ $0.566, U_{\text {jet }}=20 \mathrm{~cm} / \mathrm{s}$, and $\left.L=1 \mathrm{~cm}\right)$ at $V_{a c}=2.4 \mathrm{kV}$ and $f_{a c}=10 \mathrm{~Hz}$. The white line in each image indicates the location of a blue flame. 
Figure 10. Flow visualization for selected applied voltages at $f_{a c}=$ (a) 100 and (b) $1000 \mathrm{~Hz}$ on the baseline condition with $X_{\mathrm{F}}=0.111, X_{\mathrm{O} 2}=0.566, U_{\text {jet }}=20 \mathrm{~cm} / \mathrm{s}$, and $L=1 \mathrm{~cm}$ $\left(\mathrm{C}_{3} \mathrm{H}_{8} / \mathrm{O}_{2} / \mathrm{N}_{2}=1 / 5 / 12\right.$ and $\left.\sigma=40 \mathrm{~s}^{-1}\right)$.

Figure 11. Non-dimensional dark zone thickness using the gap distance $L$ in relation to applied frequency for the overall mixture condition of $\mathrm{C}_{3} \mathrm{H}_{8} / \mathrm{O}_{2} / \mathrm{N}_{2}=1 / 5 / 12\left(X_{\mathrm{F}}=\right.$ 0.111 and $X \mathrm{O} 2=0.566)$. External $\mathrm{AC}$ field intensity was maintained at $E=2.4 \mathrm{kV} / \mathrm{cm}$; $V_{a c}=2.4 \mathrm{kV}$ at $L=1 \mathrm{~cm}$ and $V_{a c}=4.8 \mathrm{kV}$ at $L=2 \mathrm{~cm}$.

Figure 12. Replotted result of Fig. 11 in terms of the Stokes' parameter $(\omega / 2 \sigma)^{1 / 2}$ and the normalized dark zone thickness by the maximum thickness for a given flame, where $\omega=2 \pi f_{a c}$. The overall mixture condition of $\mathrm{C}_{3} \mathrm{H}_{8} / \mathrm{O}_{2} / \mathrm{N}_{2}=1 / 5 / 12\left(X_{\mathrm{F}}=0.111\right.$ and $\left.X_{\mathrm{O} 2}=0.566\right)$. External AC field intensity was maintained at $E=2.4 \mathrm{kV} / \mathrm{cm} ; V_{\mathrm{ac}}=2.4$ $\mathrm{kV}$ at $L=1 \mathrm{~cm}$ and $V_{\mathrm{ac}}=4.8 \mathrm{kV}$ at $L=2 \mathrm{~cm}$. For easy comparison with the flame oscillation, the domain is intentionally set to be the same with Fig. 8.

Supplementary Movie 1. High-speed movie for a flow visualization with the baseline condition with no electric field.

Supplementary Movie 2. High-speed movie for a flow visualization with the baseline condition at $V_{a c}=2.4 \mathrm{kV}$ and $f_{a c}=10 \mathrm{~Hz}$.

Supplementary Movie 3. High-speed movie for a flow visualization with the baseline condition at $V_{a c}=2.4 \mathrm{kV}$ and $f_{a c}=100 \mathrm{~Hz}$.

Supplementary Movie 4. High-speed movie for a flow visualization with the baseline condition at $V_{a c}=2.4 \mathrm{kV}$ and $f_{a c}=1000 \mathrm{~Hz}$. 